\title{
The thickness of the intestinal mucous layer in the colon of rats fed various sources of non-digestible carbohydrates is positively correlated with the pool of SCFA but negatively correlated with the proportion of butyric acid in digesta
}

\author{
Mette S. Hedemann*, Peter K. Theil and K. E. Bach Knudsen \\ Department of Animal Health, Welfare and Nutrition, Faculty of Agricultural Sciences, Aarhus University, P.O. Box 50, 8830 Tjele, \\ Denmark \\ (Received 16 May 2008 - Revised 22 October 2008 - Accepted 22 October 2008 - First published online 13 January 2009)
}

\begin{abstract}
The present experiment aimed to study the influence of six sources of non-digestible carbohydrates (NDC) on the mucous layer in the colon of rats. The NDC sources used were as follows: cellulose (C); pectin (P); inulin; resistant starch (RS); barley hulls. The diets contained 108-140 g NDC/ $\mathrm{kg}$ DM. A fibre-free (FF) diet served as a control. The diets were fed to forty-eight rats for 34-41 d. The thickness of the total mucous layer in the colon was increased $(P<0.05)$ in rats fed $\mathrm{C}, \mathrm{P}$ and RS when compared with rats fed a FF diet. In the colon, positive correlations were observed between the total thickness of the mucous layer and the area of neutral mucins, the pool of SCFA and the pool of acetic acid, while it was negatively correlated with the proportion of butyrate. The total thickness of the mucous layer was not correlated with the MUC gene transcription. The transcription of the gene MUC2 was negatively correlated $(P=0.04)$, whereas the transcription of MUC3 was positively correlated $(P=0 \cdot 05)$ with the butyrate pool in the caecum. No correlations between the MUC2 or MUC3 transcription and SCFA were found in the colon. Hence, the regulation of the MUC genes differs between the compartments of the hindgut and, within compartments, the MUC genes may be regulated differently. In conclusion, a diet providing a large pool of SCFA with a low proportion of butyrate in the colon stimulates the formation of a thick mucous layer, which probably benefits intestinal health.
\end{abstract}

Non-digestible carbohydrates: Mucin: MUC2: MUC3

The mucous layer is the first line of defence between the vulnerable mucosa and the luminal contents of the bowel. It obtains its gel-forming, viscous properties from complex mucous glycoproteins, mucins, that are synthesised and secreted by goblet cells and any qualitative or quantitative changes in the mucin secretion and/or the expression patterns may affect the efficiency of the protective barrier, and this may have important physiological or pathological implications. Strengthening the mucous gel by means of dietary components could be beneficial for health reasons as mucins have been shown to be implicated in the aetiology of several gastrointestinal diseases ${ }^{(1)}$. Non-digestible carbohydrates (NDC), the fraction of carbohydrates not digested in the small intestine, may be one of the most promising nutrients in this respect. NDC has been reported to induce changes in goblet cell density, mucin synthesis and secretion ${ }^{(2-4)}$.

A characteristic feature of NDC is their physico-chemical properties such as viscosity and water-binding capacity ${ }^{(5)}$. Viscous fibre (e.g. psyllium) has been shown to increase the amount of mucus lost in faeces ${ }^{(3)}$, and the mechanical challenge of the intestinal mucosa ${ }^{(6)}$ or the bulk-forming properties of insoluble dietary fibre ${ }^{(7)}$ also increases mucin secretion.

NDC are fermented by the bacterial microflora of the gastrointestinal tract and the end products are mainly SCFA. It has been reported that SCFA stimulate mucin discharge in rats $^{(8)}$ and butyrate seems to be the most effective in modulating mucin synthesis and release ${ }^{(9)}$, and butyrate has also been shown to regulate the transcription of various MUC genes ${ }^{(4)}$.

The microflora of the gastrointestinal tract interacts with the mucous layer ${ }^{(10)}$. It has been shown that altering the microflora by the use of antibiotics ${ }^{(1)}$ or pre- ${ }^{(12)}$ or probiotics ${ }^{(13)}$ influences the mucous layer.

The thickness of the mucous layer has been evaluated using histological techniques, or indirect methods such as the expression of MUC genes and quantification of the amount of mucin in intestinal contents or faeces ${ }^{(4,6,12)}$. Histological techniques lead to the shrinkage or dissolution of the mucous layer, and hence, using these techniques, it is not possible to get a correct measure of the thickness of the

Abbreviations: BH, barley hulls; C, cellulose; FF, fibre-free; HPRT-1, hypoxanthine phosphoribosyltransferase; I, inulin; LNA, locked nucleic acid; NDC, nondigestible carbohydrates; P, pectin; RS, resistant starch.

* Corresponding author: Dr Mette S. Hedemann, fax +45899913 78, email mette.hedemann@agrsci.dk 
mucous layer ${ }^{(14)}$. The changes in the expression of the MUC genes or altered secretion of mucin indicate that the processes of the dynamic formation of the mucous layer are modified but, to our knowledge, it has never been shown how or whether this relates to changes in the thickness of the mucous layer. In vivo measurements of the thickness of the mucous layer allow us to measure the mucous layer without removing it from its natural environment and thereby preventing dehydration ${ }^{(14)}$. The method is complex and requires specialist techniques, and hence it has only been performed in a limited number of studies.

We hypothesised that NDC affect the intestinal mucous layer differentially depending on their physico-chemical characteristics, fermentabilities or prebiotic properties. A fibrefree $(\mathrm{FF})$, semi-synthetic diet was used as the control diet. Cellulose (C) and barley hulls $(\mathrm{BH})$ were chosen as inert fibre types that are only fermented to a low degree and mainly exert physical effects ${ }^{(15)}$. Pectin $(\mathrm{P})$ is a soluble fibre source, which increases the viscosity in the upper intestinal tract but is mostly fermented in the large intestine ${ }^{(16)}$. Inulin (I) was chosen due to its prebiotic properties ${ }^{(17)}$ (bifidogenic effect), whereas resistant starch (RS) was used as it increases the production of butyric acid ${ }^{(18)}$ without altering the composition of the microflora. The thickness of the mucous layer in the proximal colon was measured in vivo. We hypothesised that the effect of NDC would be most pronounced in this part of the colon due to the rapid fermentation of some of the NDC sources. Furthermore, the area of the goblet cells, the concentration and pattern of SCFA along the hindgut and the transcription of the selected genes were quantified in the caecum and the colon. In the colon, these values were related to the thickness of the mucous layer in order to determine how well these parameters describe the thickness of the mucous layer. In addition, measuring these parameters both in the caecum and the colon enabled us to elucidate the differences between the two compartments of the hindgut.

\section{Materials and methods}

\section{Animals and diets}

Male Wistar rats (average weight, 53.9 (SEM 0.6) g) were purchased from Taconic (Bomholt, Denmark). The experiment was carried out in four blocks with twelve rats in each block during a period of 3 months. The rats were housed in pairs in Plexiglas boxes $(38 \mathrm{~cm} \times 60 \mathrm{~cm})$ bedded with shavings. All rats had a chip placed subcutaneously in order to allow individual identification of the rats. The animals were kept in a temperature- $\left(25-26^{\circ} \mathrm{C}\right)$ and humidity $(50-60 \%)$ controlled environment in a $12 \mathrm{~h}$ light/dark cycle.

The rats were randomly assigned to one of six dietary treatments (eight rats per treatment). A FF diet was prepared according to Table 1. NDC sources were substituted for maize starch and the test diets were as follows: (1) FF; (2) $\mathrm{C}$; (3) P; (4) I; (5) RS; (6) BH. The chemical composition of the diets is shown in Table 2. The concentration of NDC in the test diets was $130-152 \mathrm{~g} / \mathrm{kg}$ dry diet. The diets were planned to contain the same amount of NDC. However, the amount of NDC in the various sources did deviate slightly from the expected, and hence the resulting amount of NDC in the diets differed. Inclusion of crystalline $\mathrm{C}$ in the diet resulted in a NDC content of $121 \mathrm{~g} / \mathrm{kg}$ DM and a major part of the NDC was $\mathrm{C}$. The NDC of the $\mathrm{P}$ diet was almost completely soluble. The source of $\mathrm{P}$ used $\left(\mathrm{GENU}^{\circledR}\right.$ pectin 150 USA-SAG type $\mathrm{B}$ rapid set) is a high-ester $\mathrm{P}$ with a high degree of esterification $(73.5 \%)$. The derivative of I used in the present study (Raftiline HP, Orafti, Tienen, Belgium) was a mixture of oligosaccharides with a degree of polymerisation of 3-60 (average 22-25) and the resultant content of I in the I diet was $93 \mathrm{~g} / \mathrm{kg}$ DM. The NDC in the RS diet were mainly RS of the type retrograded starch and only small amounts of NSP could be detected. The BH diet contained mainly insoluble fibres, and it had the highest content of lignin.

The rats were fed the experimental diets for 34-41 d. The duration of the feeding period differed because the measurements of the mucous layer were time consuming and measurements could only be performed on two rats per day, hence six working days were required to perform the measurements in each block. The rats were killed in a randomised order among the dietary treatment groups. The amount of feed was gradually increased from $12.5 \mathrm{~g} / \mathrm{d}$ during the first $5 \mathrm{~d}$ to $20 \mathrm{~g} / \mathrm{d}$ at the end of the experiment. The rats had free access to water.

The study complied with the guidelines of the Danish Animal Experiments Inspectorate, Ministry of Justice, Copenhagen, Denmark with respect to animal experimentation and care of animals under study.

Table 1. Composition of the experimental diets

\begin{tabular}{|c|c|c|c|c|c|c|}
\hline & \multicolumn{6}{|c|}{ Diet $(g / k g)^{*}$} \\
\hline & $\mathrm{FF}$ & C & $P$ & I & $\mathrm{RS}$ & $\mathrm{BH}$ \\
\hline Casein† & 160 & 160 & 160 & 160 & 160 & 160 \\
\hline Soyabean oil & 50 & 50 & 50 & 50 & 50 & 50 \\
\hline Maize starch & 640 & 540 & 540 & 540 & 486 & 473 \\
\hline Sugar & 100 & 100 & - & 100 & 100 & 100 \\
\hline Mineral mixtureł & 40 & 40 & 40 & 40 & 40 & 40 \\
\hline Vitamin mixture§ & 10 & 10 & 10 & 10 & 10 & 10 \\
\hline $\mathrm{C} \|$ & - & 100 & - & - & - & - \\
\hline$P q$ & - & - & 200 & - & - & - \\
\hline$I^{\star \star}$ & - & - & - & 100 & - & - \\
\hline Potato starch†† & - & - & - & - & 154 & - \\
\hline 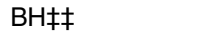 & - & - & - & - & - & 167 \\
\hline
\end{tabular}

${ }^{*}$ FF, fibre free; C, cellulose; P, pectin; I, inulin; RS, resistant starch; $\mathrm{BH}$, barley hulls.

† Miprodan 25-6 (Arla Ingredients, Viby J., Denmark) + 1\% methionine (SigmaAldrich Denmark A/S, Copenhagen, Denmark).

$\ddagger$ Mineral mixture supplied the following nutrients (per $\mathrm{kg}$ diet): calcium citrate, $13.88 \mathrm{~g}$; calcium hydrogen phosphate dihydrate, $5.08 \mathrm{~g}$; potassium hydrogen phosphate, $9.85 \mathrm{~g} ; \mathrm{KCl}, 5.61 \mathrm{~g} ; \mathrm{NaCl}, 1.74 \mathrm{~g}$; magnesium sulphate, $1.72 \mathrm{~g}$; magnesium carbonate hydroxide pentahydrate, $1.58 \mathrm{~g}$; ammonium iron(III) citrate, $0.344 \mathrm{~g}$; manganese(II) sulphate monohydrate, $45 \mathrm{mg}$; copper(II) sulphate pentahydrate, $41 \mathrm{mg}$; $\mathrm{KI}, 0.225 \mathrm{mg}$; zinc sulphate heptahydrate, $99 \mathrm{mg}$; sodium selenite, $0.585 \mathrm{mg}$

$\S$ Vitamin mixture supplied the following nutrients (per $\mathrm{kg}$ diet): retinol acetate, $750 \mu \mathrm{g}$; DL- $\alpha$-tocopherol acetate, $20 \mathrm{mg}$; menadione, $4.1 \mathrm{mg}$; choline chloride, $700 \mathrm{mg}$; folic acid, $0.7 \mathrm{mg}$; nicotinamide, $12.5 \mathrm{mg}$; calcium pantothenate, $5.0 \mathrm{mg}$; riboflavin, $2.0 \mathrm{mg}$; thiamin hydrochloride, $2.5 \mathrm{mg}$; pyridoxine chloride, $4.0 \mathrm{mg}$; cyanocobalamin, $0.03 \mathrm{mg}$; biotin, $0.25 \mathrm{mg}$; cholecalciferol, $16.25 \mu \mathrm{g}$

$\|$ Crystalline cellulose (AGF-100, Frisenette, Knebel, Denmark).

I GENU ${ }^{\circledR}$ pectin 150 grade USA-SAG type B rapid set, CP Kelco, Lille Skensved, Denmark.

${ }^{* \star}$ Raftiline HP ${ }^{\circledR}$

†† Autoclaved potato starch

抽el Toft Grovvarer A/S, Roslev, Denmark. 
Table 2. Analysed chemical composition of the experimental diets

\begin{tabular}{lcccccc}
\hline & \multicolumn{7}{c}{ Diet $(\mathrm{g} / \mathrm{kg} \mathrm{DM})^{*}$} \\
\cline { 2 - 7 } & $\mathrm{FF}$ & $\mathrm{C}$ & $\mathrm{P}$ & $\mathrm{I}$ & $\mathrm{RS}$ & $\mathrm{BH}$ \\
\hline DM $(\mathrm{g} / 100 \mathrm{~g})$ & $95 \cdot 1$ & $95 \cdot 1$ & $94 \cdot 7$ & $94 \cdot 5$ & $92 \cdot 1$ & $93 \cdot 3$ \\
Ash & 39 & 39 & 41 & 40 & 39 & 47 \\
Crude protein† & 145 & 149 & 146 & 150 & 157 & 162 \\
Starch & 615 & 501 & 529 & 552 & 611 & 471 \\
NDC $\ddagger$ and lignin & 18 & 121 & 134 & 119 & 140 & 108 \\
RS & $-\S$ & - & - & - & 115 & - \\
Fructan & $-\|$ & - & - & 93 & - & - \\
Total NSPq & $15(4)$ & $116(1)$ & $130(115)$ & $11(5)$ & $14(6)$ & $84(6)$ \\
C & 2 & 87 & 3 & 1 & 2 & 28 \\
Klason lignin & 3 & 5 & 4 & 15 & 11 & 24 \\
\hline
\end{tabular}

${ }^{\star} \mathrm{FF}$, fibre free; $\mathrm{C}$, cellulose; $\mathrm{P}$, pectin; I, inulin; RS, resistant starch; $\mathrm{BH}$, barley hulls.

$+\mathrm{N} \times 6.25$.

$\ddagger$ Non-digestible carbohydrates.

$\S$ Not determined.

\|Below the detection limit.

q Values in parentheses are soluble NSP.

\section{Measurement of the mucous gel thickness in the colon}

The rats were weighing 247 (SEM 28) g when the measurement of the mucous gel thickness in the colon was performed. The measurements were carried out as previously described ${ }^{(19)}$. The rats were anaesthetised by intra-peritoneal administration of thiobutabarbital sodium (Inactin, $120 \mathrm{mg} / \mathrm{kg}$; Sigma T-133, Sigma Chemical, St Louis, MO, USA) and subcutaneous administration of buprenorphine (Temgesic, $0 \cdot 05-0 \cdot 1 \mathrm{mg} / \mathrm{kg}$; Schering-Plough, Brussels, Belgium).

The rats were tracheotomised to facilitate spontaneous breathing. The femoral vein was cannulated for the continuous infusion of $0.9 \% \mathrm{NaCl}$ at a rate of $1 \mathrm{ml} / \mathrm{h}$. The rat was opened along the mid-line and the colon was identified and

Table 3. Mucin-staining area in the crypts $\left(\mu \mathrm{m}^{2}\right)$ and the proportion of the crypt area covered with mucin (\%) in the caecum and the colon of rats fed fibre-free diet $(F F)$, cellulose $(C)$, pectin $(P)$, inulin (I), resistant starch (RS) or barley hulls (BH)

(Mean values with their pooled standard errors)

\begin{tabular}{|c|c|c|c|c|}
\hline & \multicolumn{2}{|c|}{ Mucin-staining area } & \multicolumn{2}{|c|}{$\begin{array}{l}\text { Mucin-staining area } \\
\text { of the total crypt area (\%) }\end{array}$} \\
\hline & Neutral mucin & Acidic mucin & Neutral mucin & Acidic mucin \\
\hline \multicolumn{5}{|c|}{ Caecum } \\
\hline FF & $1693^{a b}$ & 1152 & $16 \cdot 4^{\mathrm{ab}}$ & $11 \cdot 6$ \\
\hline C & $2129^{a}$ & 972 & $19 \cdot 7^{\mathrm{a}}$ & $8 \cdot 1$ \\
\hline $\mathrm{P}$ & $1011^{\mathrm{b}}$ & 901 & $7 \cdot 2^{d}$ & $6 \cdot 6$ \\
\hline I & $1678^{\mathrm{ab}}$ & 1153 & $13 \cdot 4^{\mathrm{bc}}$ & $9 \cdot 0$ \\
\hline RS & $1268^{\mathrm{b}}$ & 1089 & $10.9^{\mathrm{cd}}$ & 9.4 \\
\hline $\mathrm{BH}$ & $1118^{\mathrm{b}}$ & 1132 & $11.0^{\mathrm{cd}}$ & $10 \cdot 7$ \\
\hline SEM & 248 & 205 & 1.9 & 1.56 \\
\hline \multicolumn{5}{|l|}{ Colon } \\
\hline FF & 3325 & 2655 & $26 \cdot 9$ & $20 \cdot 0$ \\
\hline C & 4611 & 1948 & $33 \cdot 1$ & $13 \cdot 4$ \\
\hline $\mathrm{P}$ & 3609 & 1338 & $25 \cdot 8$ & $9 \cdot 8$ \\
\hline I & 5208 & 2183 & $33 \cdot 0$ & $15 \cdot 0$ \\
\hline RS & 4279 & 3995 & $25 \cdot 9$ & $23 \cdot 0$ \\
\hline $\mathrm{BH}$ & 4714 & 2968 & $32 \cdot 3$ & $22 \cdot 2$ \\
\hline SEM & 758 & 627 & $4 \cdot 3$ & $3 \cdot 7$ \\
\hline
\end{tabular}

${ }^{a, b, c}$ Mean values in a column within a segment with unlike superscript letters were significantly different $(P<0.05)$. exteriorised. An approximately $2 \mathrm{~cm}$ long incision was made along the antimesenteric border. The incision was made $5 \cdot 7$ (SEM 0.7) $\mathrm{cm}$ distal to the caecum. The rat was placed on its left side on a microscope stage and the colon was everted through the incision and loosely draped over a truncated cone with the luminal side up. A mucosal chamber with a hole $(1.0 \mathrm{~cm}$ in diameter $)$ in the bottom was placed over the exposed mucosa, and the junction was sealed with silicone grease (VWR International, Poole, England). The chamber was filled with warm $\left(37^{\circ} \mathrm{C}\right) 0.9 \% \mathrm{NaCl}$ to keep the tissue moist and protect the mucous gel from dehydration. The mucous gel was covered with carbon particles (activated charcoal, extra pure, 1.02 184; Merck, Darmstadt, Germany) suspended in saline to visualise the surface of the otherwise near-transparent gel. A micropipette (TIP2TW1; World Precision Instruments, Hertfordshire, England) was held by a micromanipulator (MX1640R; Siskiyou Design Instruments, Grant Pass, OR, USA) and pushed into the mucous gel at an angle $(\alpha)$ of $30-40^{\circ}$ to the cell surface. The distance $(l)$ from the luminal surface of the mucous layer to the epithelial cell surface of the mucosa was measured with a digimatic indicator (543-250B; Mitutoyo, Tokyo, Japan) connected to the micromanipulator. The mucous gel thickness $(T)$ could then be calculated from the formula $T=l \times \sin \alpha$. The measurements were made at five different spots over the mucous surface. The procedure was carried out under observation through a stereomicroscope (Leica MZ12; Leica Microsystems AG, Wetzlar, Germany). The total mucous thickness was measured with $15 \mathrm{~min}$ intervals over $60 \mathrm{~min}$ to determine the basal mucous accumulation rate. Following these measurements, as much as possible of the mucous gel was removed by suction, and the thickness of the adherent mucous layer was determined.

\section{Collection of digesta and tissue samples}

After the termination of the mucous gel measurements, the rats were euthanised by an intra-venous injection of saturated $\mathrm{KCl}$. The entire gastrointestinal tract was removed and the caecum and the colon were dissected free. The intestinal contents were collected for the determination of SCFA and tissue 
Table 4. Concentration of SCFA ( $\mu \mathrm{mol} / \mathrm{g})$, the pool size $(\mu \mathrm{mol})$ and the proportions of acetic, propionic and butyric acid $(\mathrm{mol} / 100 \mathrm{~mol}$ SCFA) in the caecum and the colon of rats fed fibre-free diet (FF), cellulose (C), pectin (P), inulin (I), resistant starch (RS) or barley hulls $(\mathrm{BH})$

(Mean values with their pooled standard errors)

\begin{tabular}{|c|c|c|c|c|c|}
\hline & $\begin{array}{c}\text { SCFA } \\
(\mu \mathrm{mol} / \mathrm{g})\end{array}$ & $\begin{array}{l}\text { SCFA } \\
(\mu \mathrm{mol})\end{array}$ & $\begin{array}{c}\text { Acetic acid } \\
\text { (mol/100 mol SCFA) }\end{array}$ & $\begin{array}{c}\text { Propionic acid } \\
\text { (mol/100 mol SCFA) }\end{array}$ & $\begin{array}{c}\text { Butyric acid } \\
\text { (mol/100 mol SCFA) }\end{array}$ \\
\hline \multicolumn{6}{|c|}{ Caecum } \\
\hline $\mathrm{FF}$ & $47 \cdot 1^{\mathrm{C}}$ & $110^{c}$ & $74^{\mathrm{b}}$ & $8^{\mathrm{bc}}$ & $14^{\mathrm{a}}$ \\
\hline$C$ & $47 \cdot 7^{\mathrm{C}}$ & $134^{\mathrm{c}}$ & $82^{\mathrm{ab}}$ & $6^{c}$ & $11^{\mathrm{ab}}$ \\
\hline $\mathrm{P}$ & $70 \cdot 6^{b}$ & $279^{b}$ & $82^{\mathrm{a}}$ & $11^{\mathrm{b}}$ & $5^{\mathrm{b}}$ \\
\hline 1 & $57 \cdot 4^{\mathrm{bc}}$ & $280^{\mathrm{b}}$ & $63^{c}$ & $18^{a}$ & $19^{a}$ \\
\hline RS & $91.7^{\mathrm{a}}$ & $434^{a}$ & $75^{\mathrm{ab}}$ & $7^{c}$ & $17^{a}$ \\
\hline $\mathrm{BH}$ & $61 \cdot 7^{\mathrm{bc}}$ & $152^{c}$ & $76^{\mathrm{ab}}$ & $5^{c}$ & $16^{a}$ \\
\hline SEM & $5 \cdot 8$ & 32 & $2 \cdot 8$ & 1.1 & $2 \cdot 3$ \\
\hline \multicolumn{6}{|l|}{ Colon } \\
\hline $\mathrm{FF}$ & $32.5^{\mathrm{b}}$ & 34 & $79^{\mathrm{bc}}$ & $7^{\mathrm{b}}$ & $12^{\mathrm{a}}$ \\
\hline C & $42 \cdot 5^{\mathrm{ab}}$ & 69 & $90^{\mathrm{a}}$ & $4^{b}$ & $6^{\mathrm{b}}$ \\
\hline$P$ & $52 \cdot 8^{\mathrm{a}}$ & 94 & $81^{\mathrm{b}}$ & $12^{\mathrm{a}}$ & $6^{\mathrm{b}}$ \\
\hline I & $42 \cdot 2^{\mathrm{ab}}$ & 52 & $73^{c}$ & $14^{\mathrm{a}}$ & $13^{\mathrm{a}}$ \\
\hline RS & $56 \cdot 3^{a}$ & 95 & $86^{\mathrm{ab}}$ & $6^{\mathrm{b}}$ & $8^{\mathrm{ab}}$ \\
\hline $\mathrm{BH}$ & $45 \cdot 2^{\mathrm{ab}}$ & 66 & $83^{\mathrm{b}}$ & $4^{b}$ & $12^{\mathrm{a}}$ \\
\hline SEM & $5 \cdot 0$ & 18 & $2 \cdot 4$ & 1.4 & 1.9 \\
\hline
\end{tabular}

${ }^{a, b, c}$ Mean values in a column within a segment with unlike superscript letters were significantly different $(P<0.05)$.

samples were taken for histology and mRNA determination. In order to ensure the proximity to the point where the thickness of the mucous layer was determined, the tissue sample for histology was taken cranially and the sample for the mRNA determination was taken caudally to this point. The samples for histological examinations were immediately transferred to a $4 \%(\mathrm{v} / \mathrm{v})$ neutral-buffered formalin solution (Bie \& Berntsen, Rødovre, Denmark) and the samples for the mRNA determination were transferred to RNAlater ${ }^{\circledR}$ (R0901; Sigma), kept at $4^{\circ} \mathrm{C}$ for $24 \mathrm{~h}$ and kept at $-80^{\circ} \mathrm{C}$ until analysis.

\section{Mucin staining and morphometric measurements}

Intestinal segments were fixed in $4 \%$ neutral-buffered formalin, dehydrated, cleared and embedded in paraffin. Serial sections were cut at $4 \mu \mathrm{m}$, deparaffinised in xylene, rehydrated and stained using a combined alcian blue-periodic acid Schiff's technique for acid and neutral mucins ${ }^{(20)}$. The slides were incubated in $5 \mathrm{~g} / 1$ alcian blue (Sigma A3157), $\mathrm{pH} 2.5$ for $15 \mathrm{~min}$, then washed and incubated with $10 \mathrm{~g} / \mathrm{l}$ periodic acid (Merck 524) for $5 \mathrm{~min}$. After a wash in water, the slides were placed in Schiff's reagent (Merck 1.09033). Finally, the slides were counterstained with Mayer's haematoxylin, dehydrated and mounted.

On each slide, fifteen well-oriented crypts were selected. Indicated by blue or magenta staining, the granules of all mucous cells (goblet cells and crypt secretory cells), as well as the apical secretion of these cells, were differentiated into acidic and neutral mucin, respectively ${ }^{(20)}$. For each crypt, the area of mucin granules with a clear positive reaction for neutral or acidic mucin was determined using a computer-integrated microscope and an image analysis system (Leica QWin version 3.2.0; Leica Microsystems Imaging Solutions Ltd, Cambridge, UK). The slides were further used to determine the crypt area as previously described ${ }^{(21)}$.

\section{Chemical analyses of diets}

All feed samples were milled through a $0.5 \mathrm{~mm}$ mesh screen (Cyclotec 1093 Sample mill; Foss Tecator, Hoeganaes, Sweden) before analysis. The DM was determined by freeze-drying followed by drying at $105^{\circ} \mathrm{C}$ for $20 \mathrm{~h}$, and ash was determined by combustion at $525^{\circ} \mathrm{C}$ for $6 \mathrm{~h}^{(22)}$. Protein $(\mathrm{N} \times 6.25)$ was determined as elementary $\mathrm{N}^{(23)}$. Starch ${ }^{(24)}$ and $\mathrm{RS}^{(25)}$ were determined by the enzymatic-colorimetric assays. Fructan was determined by an enzymatic-colorimetric method $^{(26)}$, modified as previously described ${ }^{(27)}$. Neutral NSP and constituent sugars were analysed as alditol acetates by GC and uronic acids by colorimetry ${ }^{(24)}$. Klason lignin was measured gravimetrically as the residue resistant to $12 \mathrm{M}-\mathrm{H}_{2} \mathrm{SO}_{4}{ }^{(28)}$.

\section{SCFA in digesta}

Digesta samples from the caecum and the colon were analysed for SCFA by $\mathrm{GC}^{(29)}$.

\section{Total RNA isolation}

The caecum and the colon were opened lengthwise by a scissor and flushed with distilled water to remove the intestinal content. A small piece (approximately $5 \mathrm{~mm}$ ) of tissue from the caecum and the colon was fixed overnight at $4{ }^{\circ} \mathrm{C}$ in RNAlater (Sigma-Aldrich, Brøndby, Denmark), and then stored at $-80^{\circ} \mathrm{C}$ until analysis. Immediately before RNA extraction, the samples were thawed and approximately $15 \mathrm{mg}$ of tissue was weighed and finely chopped with a scalpel. The samples were then homogenised in $350 \mu$ l of RNeasy lysis buffer and the homogenates were diluted with $70 \%$ ethanol $(1: 1)$. The RNA was purified using the RNeasy mini kit (Qiagen, Albertslund, Denmark). The concentration and purity of RNA was assessed using NanoDrop ND-1000 spectrophotometer (NanoDrop Technologies, Inc., Wilmington, DE, USA). 


\section{Mucin mRNA analysis}

The purified RNA was reverse transcribed with oligo-dT and random primers using superscript III RNase H-RT kit (Invitrogen, Taastrup, Denmark). The reverse-transcribed material $(1 \mu 1)$ was amplified with TaqMan Universal PCR Master Mix (Applied Biosystems, Stockholm, Sweden). The primers and probes were designed specifically for each gene by using Primer Express 2.0 software (Applied Biosystems). At least one oligonucleotide (primer or probe) was annealed to an exon boundary (exon structures reported for human subjects were used) to avoid the amplification of genomic DNA. The amplicon length was tested after the real-time RT-PCR analysis on a $2 \%$ agarose gel and only one PCR product was amplified per gene, and the amplicon length agreed with the predicted length based on the nucleotide sequences (data not shown). The quantity of mRNA was detected by locked nucleic acid (LNA) fluorescent probes from the human library (https:// qpcr2.probefinder.com/roche2.html) using an ABI 7900HT detection system (Applied Biosystems). The transcription of target genes were normalised according to hypoxanthine phosphoribosyltransferase (HPRT-1) transcription. Ideally, a housekeeping gene should not be regulated or affected by, for example, dietary factors, types of tissues, organs, sex, developmental and/or physiological stages, and it should be constitutively expressed. The expression of HPRT-1 was tested in isolated mucosa and muscle tissues from both the caecum and the colon, and the HPRT-1 expression was comparable in all four combinations of tissue and segment (caecal epithelium, caecal muscle, colonic epithelium and colonic muscle), thus supporting that HPRT-1 is a proper housekeeping gene in this experimental design. Furthermore, no dietary effect on the HPRT-1 expression was found when correcting for the loaded amount of total RNA.

The sequences of forward primers, LNA probes and reverse primers were as follows (accession numbers are given in parentheses):

MUC-2 (U07615). 5'-GGGAACATGCAGAAGATCAACA-3', 5'-TCCTGCTC-3' (human LNA probe 15), 5'-AGCCTCTCACATTCAGCTCGAT- $3^{\prime}$

MUC-3 (U76551). 5'-CCTCTGCTTGTCCACGGATACT-3', 5'-GGTGGCAG-3' (human LNA probe 87), 5'-CGAGGATCACAAGAATCACCAA- $3^{\prime}$

HPRT-1 (NM_012583). 5'-GATTTTATCAGACTGAAGAGCTACTGTAATG- $3^{\prime}, 5^{\prime}-$

TGGTGGAG-3' (human LNA probe 22), 5'-CCAGTGTCAATTATATCTTCAACAATCAA- $3^{\prime}$

\section{Statistical analyses}

The thickness of the mucous layer was analysed using the mixed procedure (SAS Institute, Cary, NC, USA) ${ }^{(30)}$ according to the following model:

$$
Y_{\mathrm{ij}}=\mu+\alpha_{\mathrm{i}}+U_{\mathrm{j}}+\beta t+\beta_{\mathrm{i}} t+\varepsilon_{i j}
$$

where $\alpha_{\mathrm{i}}$ is the effect of the diet (i $=\mathrm{FF}, \mathrm{C}, \mathrm{R}, \mathrm{I}, \mathrm{RS}$ or BH), $U_{\mathrm{j}}$ is the effect of the rat $(\mathrm{j}=1,2, \ldots, 48)$, the effect of time, $\beta t(t=0$, $15,30,45$ and 60$)$, was used as a covariate, $\beta_{\mathrm{i}} t$ refers to the interaction between diet and time, and the term $\varepsilon_{i j} \sim N\left(0, \sigma^{2}\right)$ represents the random error. To account for the correlation between the intercept and the slope in the linear model, time was centred. The covariance structure was modulated using the option type $=\operatorname{ar}(1)$ to account for the correlation being higher for nearby times than far-apart times.

The morphological and histological data, and the concentration and proportions of SCFA, were analysed using the general linear model procedures (SAS Institute, Inc., Cary, NC, USA). The main effects of the diet and the block were assessed.

The mRNA quantities were analysed using the MIXED procedure (SAS Institute, Inc.) ${ }^{(30)}$. The effects of the NDC source were tested in a model including the block as a fixed effect and the weight at slaughter as a covariate to account for the differences in body mass. All statistics were performed at the $\Delta C t$ stage (Ct of the target gene $-C t$ of HPRT-1) ${ }^{(31)}$. The relative mRNA quantity was calculated by using the formula: Relative mRNA quantity $=2^{-\Delta \Delta C t}$.

Pearson's correlations were used to evaluate the relationship between the total thickness of the mucous layer and the area of mucin in the colon or the concentration and proportion of SCFA in digesta based on the measurements obtained from individual rats ( $n$ 48; Table 5). Furthermore, Pearson's correlations between the MUC2/MUC3 transcriptions and SCFA production were tested based on the mean levels within a dietary treatment ( $n$ 6; Table 6 ) to evaluate whether specific SCFA in the caecum or the colon affected the mRNA abundance in the respective tissues. Similarly, the correlations between the MUC2/MUC3 transcriptions and thickness of the mucous layer in the colon were tested to evaluate whether altered transcription of the studied genes was responsible for the observed differences in the total mucous layer.

The results on morphology, mucin-staining area and SCFA are expressed as least-squares means with their pooled standard errors. For the total mucous layer, the adherent mucous layer and the expression of MUC2 and MUC3, the mean

Table 5. Correlations between the thickness of the total mucous layer after $60 \mathrm{~min}$ and the mucin-staining area, the abundance of MUC genes, and the concentration and proportion of SCFA in digesta in the colon

(Correlation coefficients and $P$ values)

\begin{tabular}{|c|c|c|}
\hline & Correlation coefficient & $P$ value \\
\hline \multicolumn{3}{|c|}{ Mucin-staining area ( $n$ 48) } \\
\hline Neutral mucin & 0.37 & 0.02 \\
\hline Acidic mucin & -0.09 & 0.57 \\
\hline \multicolumn{3}{|c|}{$\begin{array}{l}\text { Mucin-staining area of the } \\
\text { total crypt area }(n 48)\end{array}$} \\
\hline Neutral mucin & 0.27 & 0.09 \\
\hline Acidic mucin & 0.04 & 0.83 \\
\hline \multicolumn{3}{|l|}{ Abundance of the } \\
\hline \multicolumn{3}{|c|}{ MUC genes $(n 6)$} \\
\hline MUC2 & 0.38 & 0.46 \\
\hline MUC3 & 0.68 & 0.14 \\
\hline \multicolumn{3}{|l|}{ SCFA pools ( $n$ 48) } \\
\hline SCFA & 0.37 & 0.02 \\
\hline Acetic acid & 0.40 & 0.01 \\
\hline Propionic acid & 0.20 & $0 \cdot 21$ \\
\hline Butyric acid & -0.06 & 0.71 \\
\hline \multicolumn{3}{|c|}{ Proportion of SCFA ( $n$ 48) } \\
\hline Acetic acid & 0.37 & 0.02 \\
\hline Propionic acid & -0.07 & 0.65 \\
\hline Butyric acid & -0.51 & 0.001 \\
\hline
\end{tabular}


Table 6. Correlations between the abundance of MUC2 and MUC3 mRNA and the mean SCFA pools and the mean proportions of SCFA in the caecum and the colon

(Correlation coefficients and $P$ values)

\begin{tabular}{|c|c|c|c|c|}
\hline & \multicolumn{2}{|l|}{ MUC2 } & \multicolumn{2}{|l|}{ MUC3 } \\
\hline & Correlation coefficient & $P$ value & Correlation coefficient & $P$ value \\
\hline \multicolumn{5}{|l|}{ Caecum } \\
\hline \multicolumn{5}{|l|}{ SCFA pools } \\
\hline Total SCFA & -0.64 & 0.17 & 0.41 & 0.42 \\
\hline Acetate & -0.55 & 0.25 & 0.22 & 0.67 \\
\hline Propionate & -0.34 & 0.50 & 0.57 & 0.24 \\
\hline Butyrate & -0.83 & 0.04 & 0.81 & 0.05 \\
\hline \multicolumn{5}{|c|}{ Proportion of SCFA } \\
\hline Acetate & 0.49 & 0.32 & -0.77 & 0.08 \\
\hline Propionate & 0.08 & 0.88 & 0.48 & 0.34 \\
\hline Butyrate & -0.70 & 0.12 & 0.81 & 0.05 \\
\hline \multicolumn{5}{|l|}{ Colon } \\
\hline \multicolumn{5}{|l|}{ SCFA pools } \\
\hline Total SCFA & 0.21 & 0.69 & 0.78 & 0.07 \\
\hline Acetate & 0.13 & 0.81 & 0.74 & 0.09 \\
\hline Propionate & 0.31 & 0.55 & 0.72 & $0 \cdot 10$ \\
\hline Butyrate & 0.71 & 0.11 & 0.12 & 0.81 \\
\hline \multicolumn{5}{|c|}{ Proportion of SCFA } \\
\hline Acetate & -0.42 & 0.41 & 0.23 & 0.65 \\
\hline Propionate & 0.43 & 0.40 & 0.21 & 0.69 \\
\hline Butyrate & 0.38 & 0.46 & -0.61 & $0 \cdot 20$ \\
\hline
\end{tabular}

values are presented. Treatment differences are considered to be significant at $\alpha=0.05$.

\section{Results}

\section{Thickness of the mucous layer}

The thickness of the total mucous layer was affected by the dietary treatment $(P<0.05$; Fig. 1). The average thickness of the total mucous layer during the $60 \mathrm{~min}$ on measurement was the lowest in rats fed the FF diet (201 (SEM 31) $\mu \mathrm{m}$ ). The average thickness of the total mucous layer of rats fed the $\mathrm{BH}$ and I diets was intermediate (241 (SEM 28) and 284 (SEM 28) $\mu \mathrm{m}$, respectively), whereas rats fed the $\mathrm{C}, \mathrm{P}$, and RS diets had a thicker mucous layer than rats fed the FF diet (319 (SEM 28) $\mu \mathrm{m}, 306$ (SEM 30) $\mu \mathrm{m}$ and 320 (SEM 34) $\mu \mathrm{m}$, respectively). There was a strong effect of time $(P<0.0001)$ on the accumulation of mucus, whereas the interaction between diet and time was non-significant, meaning

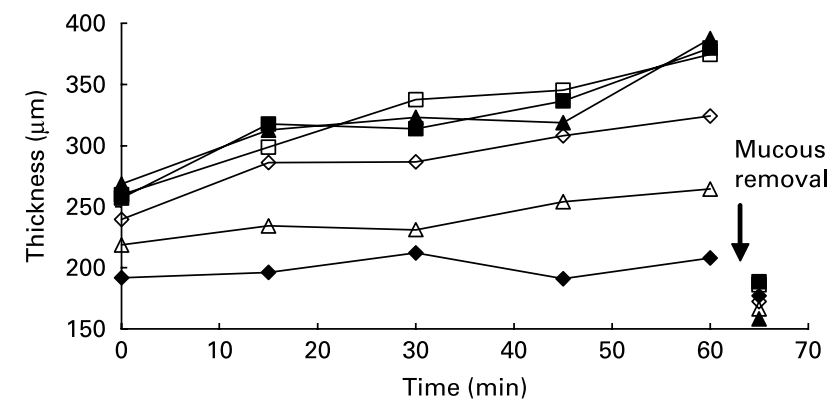

Fig. 1. Total mucous layer thickness over time and the thickness of the adherent mucous layer after mucous removal in the colon of rats fed a fibre free $(F F)$ diet $(-\diamond-; F F)$, cellulose $(-\mathbf{-}-; C)$, pectin $(-\Delta-; P)$, inulin $(-\diamond-$; I), resistant starch $(-\square-; \mathrm{RS})$ or barley hulls $(-\triangle-; \mathrm{BH})$. Values are presented as means $(n 8)$. that the accumulation of mucus during the experimental period was equal for all treatment groups. The thickness of the adherent mucous layer varied between 158 (SEM 20) $\mu \mathrm{m}$ (diet P) and 189 (SEM 18) $\mu \mathrm{m}$ (diet C), and it did not differ between the dietary treatment groups $(P>0 \cdot 10)$.

\section{Mucin staining}

The area of neutral mucin in the crypts of the caecum was the highest in rats fed the $\mathrm{C}$ diet $(P=0 \cdot 02)$, and these rats also had the largest proportion of the crypts covered by neutral mucin $(P=0.001$; Table 3$)$. The rats fed the $\mathrm{P}, \mathrm{RS}$ and $\mathrm{BH}$ diets had the smallest area of neutral mucin in the crypts of the caecum, which corresponded to the smallest proportion of the crypts covered by neutral mucin. The area of acidic mucin in the crypts and the acidic mucin-staining area of the total crypt area in the caecum was not influenced by dietary treatments. In the colon, no effect of the experimental diets was seen on the area of either neutral or acidic mucin.

\section{SCFA in digesta}

Feeding rats the RS diet elicited the highest concentration of SCFA in the digesta from the caecum (Table 4), whereas the rats fed the FF and $\mathrm{C}$ diets had the lowest concentration of SCFA in digesta. At the same time, these rats had the largest and smallest caecal pools of SCFA, respectively. In the colon, rats fed the RS and $\mathrm{P}$ diets had the highest concentration of SCFA in digesta, the concentration of SCFA in rats fed the $\mathrm{C}$, I and $\mathrm{BH}$ diets was intermediate, whereas the concentration of SCFA in colonic contents was the lowest in rats fed the FF diet. The size of the colonic pool of SCFA did not differ between the dietary treatments.

Feeding the experimental diets resulted in different proportions of SCFA in both the caecal and colonic material. 
The rats fed the I diet had the lowest proportion of acetic acid $(62.7$ (SEM 2.8) \%) but had the highest proportion of propionic and butyric acid in caecal digesta. By contrast, rats fed the $\mathrm{P}$ diet resulted in a high proportion of acetic acid (82.4 (SEM $2 \cdot 8) \%$ ) but a low proportion of butyric acid (5.2 (SEM $2 \cdot 3) \%$ ). The proportions of SCFA in caecal digesta were comparable to the rats fed the FF, $\mathrm{C}, \mathrm{RS}$ and $\mathrm{BH}$ diets. The rats fed the $\mathrm{C}$ and $\mathrm{RS}$ diets had high proportions of acetic acid (86.3$90.4 \%)$ and low proportions of propionic (3.5-5.8\%) and butyric acid $(5 \cdot 8-7.7 \%)$ in colonic contents. The rats fed the FF, I and $\mathrm{BH}$ diets resulted in a high proportion of butyric acid in the digesta of the colon and rats fed the $\mathrm{P}$ diet resulted in a high proportion of propionic acid and a low proportion of butyric acid.

\section{Mucin mRNA abundance}

The abundance of MUC2 mRNA in the caecum and the colon was not affected by the dietary treatments (Fig. 2 (A) and (B)). Feeding the experimental diets had a significant effect on the transcription of MUC3 in the caecum $(P=0.001$; Fig. 2 (C)), whereas, in the colon, no alteration of the MUC3 transcription was observed (Fig. 2 (D)).

Associations of the total mucous layer thickness and the MUC2 and MUC3 expression with caecal and colonic parameters

Significant positive correlations $(P<0.05)$ between the thickness of the total mucous layer and the area of neutral mucin, and the SCFA and acetic acid pools, as well as the proportion of acetic acid, were observed (Table 5). Furthermore, a

(A)

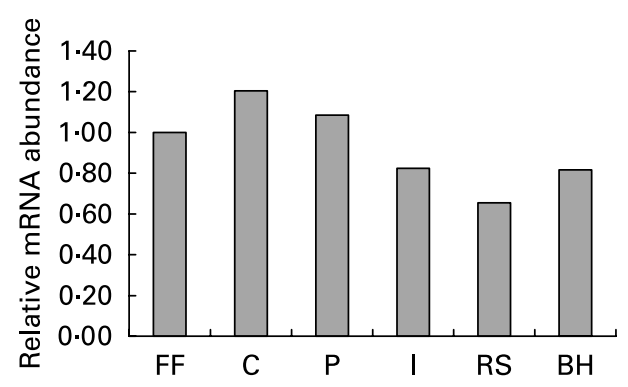

(C)

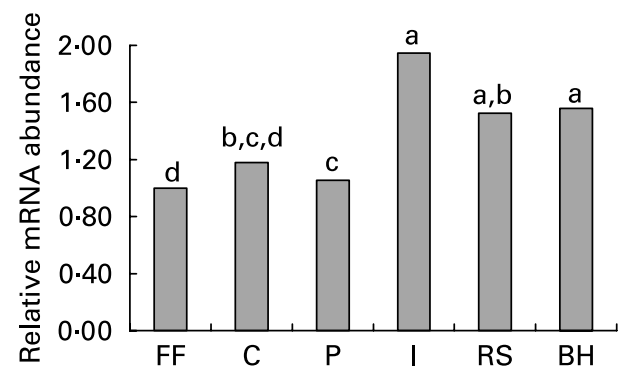

significant negative correlation $(P=0.001)$ with the proportion of butyric acid was found. The thickness of the total mucous layer was not correlated with the MUC2 expression but a high correlation between the thickness of the total mucous layer and the expression of MUC3 was observed. However, the correlation did not reach significance $(P=0 \cdot 14)$.

The abundance of MUC2 mRNA was negatively correlated with the butyrate pool in the caecum $(P=0.04$; Table 6$)$. In contrast to this, the abundance of MUC3 mRNA was positively correlated with the butyrate pool and with the proportion of butyrate in the caecum $(P=0.05)$. In the colon, no correlation between the MUC2 and MUC3 expression and the SCFA pools or the proportions of the individual fatty acids was found.

\section{Discussion}

The thickness of the total mucous layer (non-adherent and adherent) observed in the present experiment (201 (SEM 31)-320 (SEM 34) $\mu \mathrm{m}$ ) is substantially lower than the values reported previously for the colon $(\sim 830 \mu \mathrm{m})^{(19)}$, whereas they are in line with the values reported in another study ${ }^{(32)}$. The thickness of the adherent mucous layer is comparable between the studies, which suggests that the thickness of this firmly adherent gel, which has been suggested to act as a relatively stable protective barrier in the colon $^{(19)}$, is not influenced by the dietary components. This implies that it is mainly the thickness of the non-adherent mucous layer that can be modulated by, for example, diet. The accumulation of this layer by time reflects the baseline secretion of mucin by the goblet cells. The non-adherent mucous layer is believed to have lubricative properties ${ }^{(19)}$ and to trap mucosal aggressors and return them to the lumen ${ }^{(32)}$.
(B)

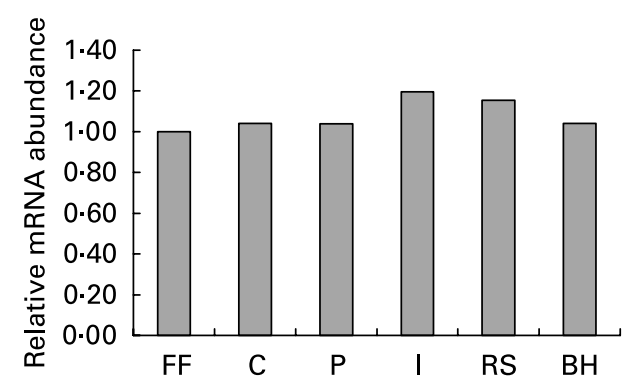

(D)

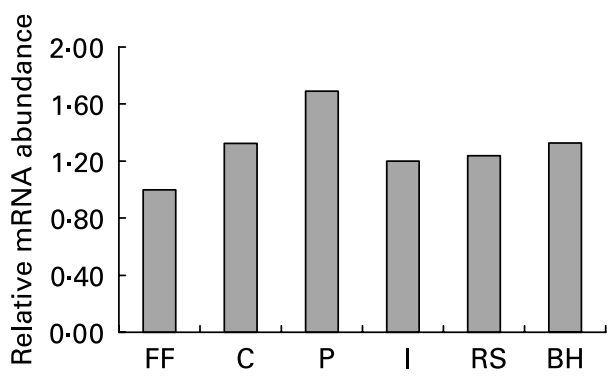

Fig. 2. Relative abundance of rat intestinal mucin 2 (MUC2) mRNA in (A) the caecum and (B) the colon and the relative abundance of rat intestinal MUC3 mRNA in (C) the caecum and (D) the colon of rats fed the experimental diets: FF, fibre free; C, cellulose; P, pectin; I, inulin; RS, resistant starch; BH, barley hulls. Changes in the mucin mRNA abundance were measured by real-time RT-PCR. The mRNA abundances of the genes are shown relative to those of rats fed the FF diet. Values are presented as means $(n 8) .{ }^{a-d}$ Mean values within segments with unlike letters were significantly different $(P<0.05)$. 
The duration of the experiment may influence the thickness of the non-adherent mucous layer as mucus accumulates over time. In the present study, mucous accumulation was observed during $1 \mathrm{~h}$, whereas considerably longer measurements (up to $6 \mathrm{~h}$ ) have been reported ${ }^{(32)}$. However, as no interaction between diet and time was observed in the present study, measuring for longer time would have increased the thickness of the mucous layer, but it would probably not have changed the conclusions regarding the effect of the diets.

The rats fed the FF diet had the thinnest mucous layer in the colon. It has been suggested that this indicates that the mucous layer of these rats had a decreased protective potential ${ }^{(32)}$. Necessity for both soluble and insoluble fibre types to increase mucosal protection has been suggested ${ }^{(32)}$. However, this is not supported by the present study where the diets were based on relatively pure fibre sources and the rats fed $\mathrm{P}$, rich in soluble fibre, and the rats fed $\mathrm{C}$, rich in insoluble fibre, both had thicker mucous layer than the rats fed the FF diet.

It has previously been suggested that a large goblet cell area corresponded to a thick mucous layer ${ }^{(33)}$. This is confirmed by the present study which showed that the area of neutral mucin correlated with the thickness of the total mucous layer, whereas no correlation with the area of acidic mucin was observed. This implies that a large area of neutral mucin corresponds to a high rate of synthesis and secretion of neutral mucin. Neutral mucin constitute the major part of the mucin in the goblet cells in colon ${ }^{(10)}$. Further investigations are needed to further elucidate the relationship between the area of neutral mucin and the thickness of the total mucous layer.

The thickness of the mucous layer was correlated with the SCFA pool and especially with the pool of acetic acid. This is in accordance with a previous study with rats fed different amounts of RS, where a high correlation between the SCFA pool in the colon and the thickness of the mucous layer was observed $^{(34)}$. In support of this, studies on perfused rat colon have shown that SCFA stimulate mucin secretion ${ }^{(9,35)}$, and the results of the present study suggest that the outcome of this is a thicker mucous layer. The thickness of the mucous layer was not correlated with the butyrate pool, which is in accordance with previous studies ${ }^{(34)}$. However, the proportion of butyric acid was negatively correlated with the thickness of the mucous layer. In the studies performed on the isolated perfused rat colon, it has been shown that butyric acid increased the secretion of mucin ${ }^{(9,35)}$. In these studies, various proportions of acetate and butyrate in the infusate were not investigated, and, furthermore, it should be emphasised that such studies are characterised by being acute or short term and it cannot be excluded that the response to butyric acid is different in an isolated colon when compared with the response after long-term exposure in an intact gastrointestinal tract where other components may influence the synthesis and secretion of mucin and hence the mucous layer.

The expression of MUC2, which is the predominant secretory mucin in the healthy intestine of rats ${ }^{(36)}$, was not affected by the dietary treatments, whereas MUC3, one of the prominent membrane-associated mucins, had a greater expression in the colon of rats fed the I, BH and RS diets. Studies on the dietary effects on the MUC gene expression are scarce, and this is, to our knowledge, the first study that aims to elucidate the effect of dietary fibre on the expression of MUC2 and MUC3 in the hindgut of rats. The MUC3 expression in epithelial goblet cells has been shown to be increased by butyrate ${ }^{(4)}$. In support of this, the expression of MUC3 in the caecum was correlated with the proportion of butyrate; however, no correlation between the butyrate pool or the proportion of butyrate and the MUC3 expression was observed in the colon. These results indicate that the expression of MUC3 is regulated differently by SCFA (butyrate) in the caecum and the colon, a similar result has been observed previously for cell proliferation $^{(37)}$, which was stimulated by SCFA in the caecum but mediated through different mechanisms in the colon. Alternatively, due to the low uptake of butyrate in the colon ${ }^{(38)}$, other factors regulate the MUC3 expression in the colon. Contrary to MUC3, the expression of MUC2 was negatively correlated with the butyrate pool in digesta in the caecum but, as with MUC3, no correlation with SCFA pool or individual fatty acids was found in the colon. These results suggest that within the same segment, MUC genes may be regulated differently by butyrate. This was also demonstrated in cultured cell lines where butyrate stimulated the MUC3 and MUC5B expression and had no effect on the MUC2 and MUC5AC expression ${ }^{(4)}$. Furthermore, the MUC genes may be regulated differently in different segments, which is supported by the fact that MUC2 is stimulated by butyrate in some cell lines ${ }^{(39)}$ but not in others ${ }^{(4,40)}$. These results, however, warrant further investigation.

In conclusion, the present study showed that feeding NDC with various properties resulted in the differences in the thickness of the total mucous layer. The thickness of the mucous layer was correlated with the area of the neutral mucin, and this histological parameter may thus be used as a predictor for the thickness of the mucous layer. SCFA, and especially acetate and butyrate, seem to be important for the regulation of the mucous layer; high concentrations of acetate increased the thickness of the mucous layer, whereas a high proportion of butyrate decreased it. In addition, the study suggested that the regulation of the MUC genes may be dependent on both the part of the gastrointestinal tract being investigated (e.g. caecum or colon) and what gene is being studied. In the light of the present study, it seems that a NDC source producing high amounts of acetate and low proportions of butyrate would promote the formation of a thick mucous layer in the colon, which has been postulated to be important for the maintenance of intestinal health.

\section{Acknowledgements}

The present investigation was supported by the Danish Veterinary and Agricultural Research Council. The authors wish to thank Kathrine Hansen Høirup, Lisbeth Märcher and Helle Handll for their excellent technical assistance. M. S. H. planned and conducted the experiment, was responsible for the SCFA analysis and histological measurements, and wrote the manuscript. P. K. T. was responsible for the analyses of the MUC genes. K. E. B. K. planned the experiment, selected the sources of NDC and was responsible for the analyses of the diets. All authors read and contributed to the finalisation of the manuscript. There are no conflicts of interest.

\section{References}

1. Corfield AP, Myerscough N, Longman R, et al. (2000) Mucins and mucosal protection in the gastrointestinal tract: new 
prospects for mucins in the pathology of gastrointestinal disease. Gut 47, 589-594.

2. Lundin E, Zhang JX, Huang CB, et al. (1993) Oat bran, rye bran, and soybean hull increase goblet cell volume density in the small intestine of the golden hamster. A histochemical and stereologic light-microscopic study. Scand J Gastroenterol 28, $15-22$.

3. Satchithanandam S, Klurfeld DM, Calvert RJ, et al. (1996) Effects of dietary fibers on gastrointestinal mucin in rats. Nutr Res 16, 1163-1177.

4. Gaudier E, Jarry A, Blottiere HM, et al. (2004) Butyrate specifically modulates MUC gene expression in intestinal epithelial goblet cells deprived of glucose. Am J Physiol Gastrointest Liver Physiol 287, G1168-G1174.

5. Dreher ML \& Sungsoo S (1987) Physicochemical and functional properties of dietary fiber as related to bowel function and food use. In Handbook of Dietary Fibre, pp. 137-180 [ML Dreher and S Sungsoo, editors]. New York/Basel: Marcel Dekker Inc.

6. Enss ML, Schmidt-Wittig U, Honer K, et al. (1994) Mechanical challenge causes alterations of rat colonic mucosa and released mucins. Alterations of mucosa and mucins. J Exp Anim Sci 36, $128-140$.

7. Tanabe H, Sugiyama K, Matsuda T, et al. (2005) Small intestinal mucins are secreted in proportion to the settling volume in water of dietary indigestible components in rats. J Nutr 135, 2431-2437.

8. Sakata T \& Setoyama H (1995) Local stimulatory effect of SCFA on the mucus release from the hindgut mucosa of rats (Rattus norvegicus). Comp Biochem Physiol 111A, 429-432.

9. Shimotoyodome A, Meguro S, Hase T, et al. (2000) Short chain fatty acids but not lactate or succinate stimulate mucus release in the rat colon. Comp Biochem Physiol A Mol Integr Physiol 125, 525-531.

10. Deplancke B \& Gaskins HR (2001) Microbial modulation of innate defense: goblet cells and the intestinal mucus layer. Am J Clin Nutr 73, 1131S-1141S.

11. Smirnov A, Perez R, Amit-Romach E, et al. (2005) Mucin dynamics and microbial populations in chicken small intestine are changed by dietary probiotic and antibiotic growth promoter supplementation. J Nutr 135, 187-192.

12. Kleessen B, Hartmann L \& Blaut M (2003) Fructans in the diet cause alterations of intestinal mucosal architecture, released mucins and mucosa-associated bifidobacteria in gnotobiotic rats. Br J Nutr 89, 597-606.

13. Mack DR, Ahrne S, Hyde L, et al. (2003) Extracellular MUC3 mucin secretion follows adherence of lactobacillus strains to intestinal epithelial cells in vitro. Gut 52, 827-833.

14. Strugala V, Allen A, Dettmar PW, et al. (2003) Colonic mucin: methods of measuring mucus thickness. Proc Nutr Soc 62, 237-243.

15. Yang MG, Manohara K \& Young AK (1969) Influence and degradation of dietary cellulose in cecum of rats. J Nutr 97, 260-264.

16. Harris PJ, Tasman-Jones C \& Ferguson LR (2000) Effects of two contrasting dietary fibres on starch digestion, short-chain fatty acid production and transit time in rats. $J$ Sci Food Agric 80, 2089-2095.

17. Gibson GR, Beatty ER, Wang X, et al. (1995) Selective stimulation of bifidobacteria in the human colon by oligofructose and inulin. Gastroenterology 108, 975-982.

18. Henningsson AM, Margareta E, Nyman GL, et al. (2003) Influences of dietary adaptation and source of resistant starch on SCFA in the hindgut of rats. Br J Nutr 89, 319-328.

19. Atuma C, Strugala V, Allen A, et al. (2001) The adherent gastrointestinal mucus gel layer: thickness and physical state in vivo. Am J Physiol Gastrointest Liver Physiol 280, G922-G929.
20. Bancroft JD \& Gamble M (2002) Theory and Practice of Histological Techniques, 5th ed. London: Churchill Livingstone.

21. Hedemann MS, Eskildsen M, Laerke HN, et al. (2006) Intestinal morphology and enzymatic activity in newly weaned pigs fed contrasting fiber concentrations and fiber properties. J Anim Sci 84, 1375-1386.

22. AOAC (1990) AOAC. Official Methods of Analysis. Arlington, VA: Association of Official Analytical Chemists.

23. Hansen B (1989) Determination of nitrogen as elementary-N, an alternative to Kjeldahl. Acta Agric Scand 39, 113-118.

24. Bach Knudsen KE (1997) Carbohydrate and lignin contents of plant materials used in animal feeding. Anim Feed Sci Technol 67, 319-338.

25. McCleary BV \& Monaghan DA (2002) Measurement of resistant starch. $J$ AOAC Int 85, 665-675.

26. Larsson K \& Bengtsson S (1983) Bestämning av lättilgängelig kolhydrater i växtmaterial (Determination of readily available carbohydrates in plant material) Chemistry Methods Report No. 22, Natl. Lab. Agric. Chem, Uppsala, Sweden.

27. Hindrichsen IK, Wettstein HR, Machmuller A, et al. (2004) Effects of feed carbohydrates with contrasting properties on rumen fermentation and methane release in vitro. Can J Anim Sci 84, 265-276.

28. Theander O \& Åman P (1979) Studies on dietary-fibers.1. Analysis and chemical characterization of water-soluble and waterinsoluble dietary-fibers. Swedish J Agric Res 9, 97-106.

29. Jensen MT, Cox RP \& Jensen BB (1995) Microbial-production of skatole in the hind gut of pigs given different diets and its relation to skatole deposition in backfat. Anim Sci 61, 293-304.

30. Littell RC, Milliken GA, Stroup WW, et al. (1996) SAS ${ }^{\circledR}$ System for Mixed Models. Cary, NC: SAS Institute Inc.

31. Theil PK, Sorensen IL, Therkildsen M, et al. (2006) Changes in proteolytic enzyme mRNAs relevant for meat quality during myogenesis of primary porcine satellite cells. Meat Sci 73, 335-343.

32. Brownlee IA, Havler ME, Dettmar PW, et al. (2003) Colonic mucus: secretion and turnover in relation to dietary fibre intake. Proc Nutr Soc 62, 245-249.

33. Brunsgaard G (1998) Effects of cereal type and feed particle size on morphological characteristics, epithelial cell proliferation, and lectin binding patterns in the large intestine of pigs. J Anim Sci 76, 2787-2798.

34. Toden S, Bird AR, Topping DL, et al. (2007) Dose-dependent reduction of dietary protein-induced colonocyte DNA damage by resistant starch in rats correlates more highly with caecal butyrate than with other short chain fatty acids. Cancer Biol Ther 6, 253-258.

35. Barcelo A, Claustre J, Moro F, et al. (2000) Mucin secretion is modulated by luminal factors in the isolated vascularly perfused rat colon. Gut 46, 218-224.

36. Renes IB, Boshuizen JA, Van Nispen DJPM, et al. (2002) Alterations in MUC2 biosynthesis and secretion during dextran sulfate sodium-induced colitis. Am J Physiol Gastrointest Liver Physiol 282, G382-G389.

37. Zhang J \& Lupton JR (1994) Dietary fibers stimulate colonic cell proliferation by different mechanisms at different sites. Nutr Cancer 22, 267-276.

38. Remesy C \& Demigne C (1976) Partition and absorption of volatile fatty acids in the alimentary canal of the rat. Ann Rech Vet 7, 39-55.

39. Hatayama H, Washita J, Kuwajima A, et al. (2007) The short chain fatty acid, butyrate, stimulates MUC2 mucin production in the human colon cancer cell line, LS174T. Biochem Biophys Res Commun 356, 599-603.

40. Augenlicht L, Shi L, Mariadason J, et al. (2003) Repression of MUC2 gene expression by butyrate, a physiological regulator of intestinal cell maturation. Oncogene 22, 4983-4992. 